\title{
SUCCESSIVE APPROXIMATIONS OF SOLUTIONS TO THE CAPUTO FRACTIONAL DIFFERENTIAL EQUATIONS
}

\author{
M. PAlani AND A. UsACHEV*
}

Abstract. We consider an initial value problem involving a single term Caputo differential equation of fractional order strictly greater than one. For those with right hand sides that satisfy an Osgood type condition, we show that there exist successive approximations which converge to the solution at an exponential rate. As an application of this result, we study the Ulam-Hyers stability of these problems.

Mathematics subject classification (2010): 34A08, 34A45, 34D20, 26 A33. equations.

Keywords and phrases: Caputo derivative, Osgood condition, successive approximations, stability of

\section{REFERENCES}

[1] R. P. AgARWAL, V. LAKShMikANTHAM, Uniqueness and nonuniqueness criteria for ordinary differential equations, Vol. 6 of Series in Real Analysis, World Scientific Publishing Co., Inc., River Edge, NJ, 1993.

[2] C. Calderón, V. N. Vera De Serio, Successive Approximations and Osgood's Theorem, Rev. Unión Mat. Argent.,40, 3-4 (1997), 73-81.

[3] K. Diethelm, The Analysis of Fractional Differential Equations, Lecture Notes in Mathematics, Springer-Verlag Berlin, 2004.

[4] D. H. Hyers, G. Is AC, TH. M. Rassias, Stability of functional equations in several variables, Birkhäuser, 1998.

[5] S.-M. Jung, Hyers-Ulam-Rassias stability of functional equations in mathematical analysis, Hadronic Press, Palm Harbor, 2001.

[6] A. Kilbas, H. Srivastava, J. Trujillo, Theory and applications of fractional differential equations, North-Holland Mathematics Studies, 204. Elsevier Science B.V., Amsterdam, 2006.

[7] K. D. KuCChE, S. SutAR, Stability via successive approximation for nonlinear implicit fractional differential equations, Moroccan J. Pure. Appl. An., 3, 1 (2017), 36-55.

[8] V. Lakshmikantha, T. G. Bhaskar, S. Leela, Fractional differential equations with a Krasnoselskii-Krein type condition, Nonlinear Anal.-Hybri., 3, (2009), 734-737.

[9] V. LaKshmikantham, A. S. VATSAla, General uniqueness and monotone iterative technique for fractional differential equations, Appl. Math. Lett., 21, 8 (2008), 828-834.

[10] Y. LIU, J. WU, Uniqueness results and convergence of successive approximations for fractional differential equations, Hacet. J. Math. Stat., 42, 2 (2013), 149-158.

[11] W. OKRASIŃSKI, Nontrivial Solutions to Nonlinear Volterra Integral Equations, SIAM J. Math. An., 22, 4 (1991), 1007-1015.

[12] W. F. OsGOOD, Beweis der Existenz einer Lösung der Differentialgleichung $\frac{d y}{d x}=f(x, y)$ ohne Hinzunahme der Cauchy-Lipschitz'schen Bedingung, Monatsh. Math. Phys., 9, 1 (1898), 331-345.

[13] M. Palani, C. C. TISDell, A. Usachev, Qualitative results for solutions to nonlinear Caputo differential equations that satisfy a generalised Osgood condition, Frac. Diff. Cal., 8, 1 (2018), 151164.

[14] J. WANG, L. LV, Y. ZHOU, Ulam stability and data dependence for fractional differential equations with Caputo derivative, Elect. J. Qualitative Th. Diff. Eq., 63, (2011), 1-10.

[15] A. WinTneR, On the Convergence of Successive Approximations, Am. J. Math., 68, 1 (1946), 13-19. 